\title{
GREEN TEA CATECHIN LOADED NANODELIVERY SYSTEMS FOR THE TREATMENT OF PANDEMIC DISEASES
}

\author{
SATHEESH BABU NATARAJAN ${ }^{1,2 *}$, SURIYAKALA PERUMAL CHANDRAN ${ }^{1,3}$, ANJANEYULU VINUKONDA $^{4}$, \\ SENTHIL RAJAN D
}

${ }^{1}$ Department of Formulation Development, Tropicana Herbals, Dindigul, Tamil Nadu, India. ${ }^{2}$ Department of Pharmaceutics, Faculty of Pharmacy, Lincoln University College, Kota Bharu, Malaysia. ${ }^{3}$ Department of Biochemistry, Faculty of Medicine, Lincoln University College, Kota Bharu, Malaysia. ${ }^{4}$ Department of Formulation Development, Alembic Pharmaceuticals Ltd. and Research, Ahmadabad, Gujarat, India. ${ }^{5}$ Department of Pharmaceutics, Swamy Vivekanandha College of Pharmacy, Tiruchengode, Tamil Nadu, India. Email: satheeshbabumpharm@gmail.com

Received: 14 May 2018, Revised and Accepted: 22 March 2019

\begin{abstract}
Tea (Camellia sinensis, Family: Theaceae) is one of the extremely consumed beverages around the world, behind to water. The brew tea is the merely food product contains abundant quantity of the catechins. Green tea is the least processed and thus contains rich antioxidant, polyphenols, especially catechin called epigallocatechin-3-gallate (EGCG), which is whispered to be responsible for a wide range of the health benefits. The key to the amazing health benefits that are derived from green tea is that the leaves are steamed which preserves the EGCG compound from being oxidized. However, the other varieties of teas are under go fermentation process, which breaks down the potential EGCG and destroy from its healing properties. In reality, green tea has very extensive history dating back thousands and thousands of years ago. However, the pharmacological efficacy and stability of green tea catchiness are primarily depended on the formulation and way to drink to alleviate the deadly diseases with scientific evidence. Nanotechnology is a vibrantly emerging field especially in the pharmaceutical industry to explore a lot of application. The promising nano-delivery system used to enhance the therapeutic efficacy with a minimal dose, minimize the dose-related toxicity, target delivery, site-specific delivery, and controlled/sustain the delivery application. In recent decades, the application of nanotechnology has been utilized for phytopharmaceutical industry including green tea catechins to maximize the health benefits. In this review, we tried our level best retrieve the value of information on nanodelivery application of green tea catchiness for various devastating diseases.
\end{abstract}

Keywords: Camellia sinensis, Green tea, Catechine, Flavonoids, Nanoparticles, Nanoemulsion, Liposomes.

(C) 2019 The Authors. Published by Innovare Academic Sciences Pvt Ltd. This is an open access article under the CC BY license (http://creativecommons. org/licenses/by/4. 0/) DOI: http://dx.doi.org/10.22159/ajpcr.2019.v12i5.27308

\section{INTRODUCTION}

Since the ancient era, herbals and natural products are being used to devastate many deadly diseases including cancer, diabetes, cardiovascular complications, and psychological disorders. Unlike widely used modern medicine, herbal formulations have numerous vital phytoconstituents that all work simultaneously to eradicate the diseases [1-4]. However, the health benefits of herbal medicines not extensively delivered to heal the diseases due to deprived acceptance by many physicians, and lack of scientific and clinical evidence [5-7]. The majority of the phytoconstituent before get absorbed into the systemic circulation, deactivated by a wide range of gastrointestinal $\mathrm{pH}$, biological enzymes, and liver metabolism [8-10]. Consequentially, the optimum therapeutic outcome of herbal drugs may not attain. If the drug does not achieve the optimum concentration to the affected region at "minimum effective level," then there will be no therapeutic outcome of the drug. During recent decades, nano drug delivery technology has been utilized for a wide range of pharmaceutical compounds to deliver sustains or controlled manner to treat various chronic illness [11]. After successful preclinical and clinical research, numerous nanoformulations have been existed to alleviate various chronic illness and cosmetic applications [12,13].

Tea (Camellia sinensis, Theaceae) is one of highly consumed beverages around the globe [14-17]. In addition to being the most widely consumed tea, it is the only food product known to contain substantial levels of the catechins $[18,19]$. All tea plants belong to the same species C. sinensis; but local growing conditions (altitude, climate, and soils) vary, resulting in a multitude of distinctive leaves [20,21]. The way the leaves are processed, however, is even more important in developing the individual characteristics of the three predominant types of tea:
Green, black, and oolong. Green tea is the least processed and thus contains rich antioxidant, polyphenols, remarkably a catechin called epigallocatechin-3- gallate (EGCG), which is believed to be accountable for most of the health benefits [22-26]. The following catechins are abundantly present in green tea including (-)-EGCG ( 59\% from total catechins); (-)-EGC ( 19\% from total catechins); (-)-epicatechin (EC)-3gallate ( $14 \%$ from total catechins); and (-)-EC ( $6 \%$ from total catechins). It also carries gallic acid and other phenolic compounds including chlorogenic acid and caffeic acid, and flavonols such as myricetin, kaempferol, and quercetin [27]. Green tea is made by steaming the fresh leaves, rendering them soft, pliable, and preventing them from fermenting or changing color $[28,29]$. After steaming, the leaves are rolled, then spread out and dried with hot air until they become crispy. The resultant tea has greenish-yellow in color, slightly astringent flavor. Green tea is extremely famous beverage in all around the world. It not only captures the taste, aroma and color of spring but also delivers this delightful bouquet along with the highest concentration of beneficial phytoconstituents and the low level of caffeine compared to all other teas [30-32]. The key to the amazing health benefits that are derived from consuming green tea is that, the leaves are steamed which preserves the EGCG compound from being oxidized [33,34]. Other varieties of teas are fermented but which rupture the vital compound EGCG and spoil its healing ability. In fact, green tea has very long historical background since few 1000 years ago.

Nanoparticle is an emerging drug delivery system which has applied to the vast majority of herbal phytoconstituents to attain greater therapeutic efficacy [35,36]. These delivery systems have widespread advantages including enhanced drug loading, protect against gastrointestinal $\mathrm{pH}$, escape form first-pass metabolism, ability to achieve prolonged release, and improved stability [37-39]. 
Encapsulation of herbal extracts into nanocarrier system has certain added advantages embrace with sustain/controlled drug release, sitespecific drug release, improved enzymatic stability, and increased intracellular drug release [40-43]. We have done extensive literature review on the health benefits of catechin from green tea extract (GTE) and their pharmaceutical and biological challenges toward achieve maximum therapeutic potential and also enlighten the application of nano drug delivery utilized to improve its pharmacological and pharmaceutical attributes.

\section{CHALLENGES OF DEVELOPING GREEN TEA CATECHIN AS THERAPEUTIC AGENT}

\section{Bioavailability challenges}

A major challenge in extrapolate the therapeutic activities of green tea polyphenols in vitro to possible effects in vivo bioavailability [44]. The deprived bioavailability of EGCG might be attributed to several factors: (a) The instability of EGCG in alkaline or neutral condition, (b) low cellular uptake due to high aqueous solubility and poor hydrophobicity to cross cell membrane; (c) metabolic transformations such as methylation, glucuronidation and sulfation [21], and (d) active efflux effect of many polyphenolic compounds by the Multidrug ResistanceAssociated Protein 2 [45-50]. Administration of decaffeinated green tea to the rats, the plasma bioavailability of EGCG, EGC, and epicatechin EC was $0.1 \%, 14 \%$, and $31 \%$, respectively, compared with mice model, whose absolute plasma bioavailability of EGCG was $26.5 \%$ [51]. Numerous researches on the pharmacokinetic profile of tea polyphenols in humans have been reported till date [52-55]. The oral administration of green tea at dose $20 \mathrm{mg} / \mathrm{kg}$ body weight resulted in plasma $\mathrm{C}_{\max }$ for EGCG at $78 \mathrm{ng} / \mathrm{mL}$; it was very low to the micromolar concentration usually required for in vitro activity. Thus, the extent of bioavailability and therapeutic efficacy of GTE primarily depends on the route of administration and site of the organ [56-59].

\section{Biological stability of GTE}

The EGCG is unstable phytoconstituent which is effortlessly prone to oxidation reaction. The researcher Friedman reported that EGCG on green tea showed a decrease in EGCG concentration after stored at the dry condition at $20^{\circ} \mathrm{C}$ during 6 months due to the oxidation process [60]. TCs as a mixture in alkaline solutions $(\mathrm{pH}>8)$ were highly unstable and degraded almost completely within a few minutes, whereas in acidic solutions $(\mathrm{pH}<4)$ it was highly stable. From the $\mathrm{pH} 4-8$, the stability of GTCs was $\mathrm{pH}$-dependent, i.e., the lower the $\mathrm{pH}$, the greater, the stability. Four EC isomers demonstrated varying stability in alkaline solutions with EGCG and EGC being equally instable, and EC and ECG being relatively stable [61-64].

\section{Stability issues during green tea processing}

It is well documented that polyphenol exists in tea is responsible for health-related beneficial effects. The content and stability of the tea polyphenols mostly depend on several production parameters including vascular plant, harvesting season, age of the plant, environmental condition, and process condition. It is well documented that process condition is one of the vital factors that determine the quality of the tea product [65].

On the other hand, EGCG is unstable to light and warm condition. The degradation temperature for EGCG is $85^{\circ} \mathrm{C}$ while exposed to radiation for $1 \mathrm{~h}$. Therefore, infundation extraction method should be performed in extreme cold condition and the $\mathrm{pH}$ is adjusted to 4 using phosphoric acid [66]. This treatment could increase EGCG concentration much higher in methanolic solution, while the green tea after infundation process that underwent the temperature decreasing process until $22^{\circ} \mathrm{C}$ showed that EGCG concentration was $30 \%$ lower than methanol. Green tea that underwent $90^{\circ} \mathrm{C}$ infundation method during $30 \mathrm{~min}$ without $\mathrm{pH}$ alteration exhibited similar to methanolic solvent. This study reported that the importance of extreme decreasing temperature and decreasing $\mathrm{pH}$ to 4 after infundation process and the resultant EGCG concentration was 6.7\% [67]. Prayong et al., 2007, reported that the EGCG concentration was $0.21-9.63 \%$ [68], whereas the EGCG concentration end in brewed tea was 2.8-3.96\% [69]. Besides that, EGCG concentration with extreme decreasing temperature and adding phosphoric acid till pH 4 was 35\% [70]. The second most abundant flavonoid present in green tea leaves is catechin. Tea catechins undergo degradations and epimerization in the aqueous condition during thermal processing. It is known that thermal degradation and epimerization of green tea catechins follow pseudo-first-order reaction kinetics in the aqueous solvent system [71].

\section{NANO DRUG DELIVERY APPROACH OF GREEN TEA}

EGCG offers enormous health benefits since it is ample accessible and inexpensive to extract and isolate from the tea leaf; it may be administered orally and proven safety profile. The usage of EGCG in clinical practice was greatly hampered due to diminutive half-life, short stability, and less bioavailability [71]. The stability issues of orally ingested EGCG were evidenced that the detected plasma concentration was recorded very poor (0.2-2\%). In addition, the effective antitumoral concentration of EGCG in vitro is generally an order of magnitude higher than the levels measured in vivo, which restricts its effectiveness [72]. Moreover, EGCG has poor target specificity. Therefore, a technique that will increase the EGCG stability, bioavailability, and cellspecific delivery is highly important to attain maximum therapeutic efficacy. Recently, the nano delivery technique was introduced to enhance the pharmacokinetic and pharmacodynamic of the efficacy of chemotherapeutic agents to inhibits, slow-down, or revert the cancers. The encapsulation of EGCG into a specific nanocarrier can increase its solubility and bioavailability, protect it from premature degradation, provide prolonged circulation time and induce higher levels of target specificity [73-76]. Polymeric nanoparticles have a promising delivery system in the field of the biomedical field due to its biocompatibility, biodegradability, possibility to control the rate of polymer degradation and release rate, mechanical strength, and high structure versatility $[77,78]$. With these positive prospects, the various polymeric nanoparticulate drug delivery systems have been developed and investigated to enhance the therapeutic potential of green tea polyphenols. In this review paper, we tried our level best to extract and compiled the most vital information related to the nano delivery and its application toward green tea polyphenols.

\section{Chitosan nanoparticles (CSNP)}

Catechins found in tea leaf have gained significant attention as a result of their favorable pharmacological properties including cardioprotective, neuroprotective, and anticancer effects [79]. However, their therapeutic prospects are hampered due to their deprived oral bioavailability, poor stability, and intestinal absorption. To enhance the oral bioavailability, $(+)$-catechin (C) and (-)-EGCG were encapsulated into CS-NP drug delivery system. Victimization excised mouse small intestine in victimization chambers, encapsulation considerably increased $(\mathrm{p}<0.05)$ internal organ absorption. The additive amounts transported after encapsulation were significantly higher, i.e., 302 versus $206 \mathrm{ng} / \mathrm{cm}$ and 100 versus $58 \mathrm{ng} / \mathrm{cm}$ for C and EGCG, respectively. The mechanism of enhanced absorption was not through an impact of CSNPs on internal organ either paracellular or transcellular transport mechanism. However, it was possible as a result of the stabilization of catechins after encapsulated into CSNP [80]. The researcher Alotaibi et al., 2013, also encapsulated EGCG into Poly (lactic-co-glycolic acid) (PLGA) based polymeric nanoparticles and investigated the effect of DNA damage against lymphocytes of healthy and colorectal cancer patients pretreated with oxaliplatin of satraplatin. The obtained results concluded that the PLGA encapsulated EGCG significantly intensified DNA damage levels in a dose-dependent manner. In contrast, free EGCG promoted a reduction in DNA damage [77].

\section{Solid lipid nanoparticles (SLN)}

Manea, Ana-Maria et al., 2014, developed GTE loaded SLN by high shear homogenization technique and investigated the antioxidant potential and antimicrobial activity. The antioxidant efficacy of GTE loaded SLNs, was higher than free-SLNs or GTE in bulk as a result of a synergistic effect between the complex structural lipid matrix and bioactive GTE 
encapsulated. The use of the two surfactants Tween 20 and Tween 80 , as well as two different concentrations of GTE (0.1 and $0.17 \%)$, and did not produce any significant variation. The highest antioxidant (99.6\%) was obtained when Tween 20 was used as a surfactant and the concentration of GTE $(0.17 \%)$, while the less antioxidant $(87.3 \%)$ was exhibited when Tween 80 used as a surfactant and the concentration of GTE was $0.1 \%$ [81]

Green tea catechins constitute about $8-15 \%$ of total dry tea weight. The most abundant catechin is EGCG, which accounts for $25-55 \%$ of total catechins. One cup of green tea made using a $2.5 \mathrm{~g}$ tea bag contains about 100 mg of EGCG $[82,83]$. Consumption of EGCG has been reported to have several health benefits including antioxidant, anti-inflammatory, anti-tumorigenic, and antiangiogenic properties as established by Chyu et al., 2004 [84].

De Pace et al., 2013, developed EGCG loaded into liposomes and chitosan-coated liposomes, with the vesicular size $\leq 100 \mathrm{~nm}$ in diameter to enhance the stability. The nanoliposomal delivery system has been drastically enhanced the stability of EGCG in both phosphate-buffered saline and Eagle's minimum essential (EME) cell culture medium. The free EGCG in EME medium was completely degraded after 8 days at $4^{\circ} \mathrm{C}$. However, EGCG loaded liposomes and chitosan-coated liposomes were degraded $62 \%$ and $38 \%$, respectively, at the same conditions and initial concentrations. After 1 -h incubation at $37^{\circ} \mathrm{C}$, the EGCG degradation rates of $0.5 \mathrm{mM}$ of free EGCG, EGCG loaded liposomes, and chitosancoated EGCG loaded liposomes in EME medium were 100\%, 46\%, and $32 \%$, respectively [85].

It is well established that EGCG has not readily absorbed in humans and animal models. The Barras et al., 2009, had conducted the pharmacokinetic and bioavailability investigation of tea leaf catechins using rat models. The plasma peak concentrations of green tea catechins exhibit at 2-4 h after oral administration. The absolute bioavailability of EGCG after intragastric administration of decaffeinated green tea is about $0.1 \%$ in rats [86]. Consistent with this result, the bioavailability of EGCG is $0.14 \%$ in males and females after consumed tea which contains $400 \mathrm{mg}$ catechins for $24 \mathrm{~h}$ period. The peak plasma EGCG concentration is around $0.15 \mu \mathrm{M}$ after drinking two cups of green tea. A majority of published cell culture studies have used EGCG at physiologically irrelevant concentrations in the range of $10-200 \mu \mathrm{M}$. Since EGCG at lower, and physiological relevant (achievable by oral administration) concentrations have little or very limited efficacy and thus, it is highly important to enhance the EGCG bioavailability, and the nanoparticulate drug delivery technology appears to be an appropriate concept to address these issues [87]. In fact, numerous researches revealed that nanoencapsulation system has been one of the prominent nano delivery systems which significantly increases EGCG stability and improves drug release rate, which partially contributes to the increased cellular uptake of EGCG. In another research reported that the chitosanbased nanoparticulate systems have capable to enhance the EGCG bioavailability [87-90]. Dube et al., 2013, compared the intestinal absorption of free EGCG and nano-EGCG (CSNP) using excised mouse jejunum. They added $50 \mu \mathrm{M}$ of free and nano-EGCG in the mucosal chambers and collected the transported EGCG in the serosal chambers after $3 \mathrm{~h}$ time interval, and found that nano-EGCG had about two-fold higher accumulative transported than free EGCG. The enhanced stability of EGCG and improved transcellular transport process was achieved in nanoparticle system, but not paracellular transport mechanism, may partially contribute to the enhanced intestinal absorption [91]. After reaching the apical membrane of intestinal epithelial cells, most of the nanoparticles cross enterocytes through transcellular transport mechanism. Nanoparticles are internalized into enterocytes and then transported across enterocytes. The particle size $\leq 500 \mathrm{~nm}$ in diameter is internalized through both clathrin- and caveolae-mediated endocytosis. The process of endocytosis can be enhanced by modifying nanoparticles, for example, by coating with polyethylene glycol or positive charges on the surface of nanoparticles [80]. The researcher Dube et al., 2013, measured the plasma concentrations of EGCG in mice after oral administration of either free EGCG or EGCG encapsulated CSNP. Compared to free EGCG, EGCG-loaded CSNP increased plasma EGCG concentrations by a factor of 1.5 [46]. EGCG nano lipidic particles increased the oral bioavailability by $\geq 2$ folds as compared to free EGCG in rats as documented by Wang et al., 2013 [87].

\section{Gold nanoparticles for tumor targeting}

The tea based gold nanoparticles (T-AuNPs) [93] have evidenced remarkable in vitro stability in various buffer solution including saline, histidine, HSA, and cysteine solutions. T-AuNPs with phytochemical coatings have shown important affinity toward prostate (PC-3) and breast cancer (MCF-7) cells. This study reported on the cellular acquisition of T-AuNPs through endocytosis into the PC-3 and MCF7 cells. The T-AuNPs follows all principles of green chemistry and are found to be non-cyanogenic as evaluated by MTT assays. This true biogenic green nanotechnological process T-AuNPs paving excellent opportunities for their applications in molecular imaging and clinical therapy [94].

Several reports have described the results of gold NPs in conjugation with EGCG for cancer treatment. The AuNPs loaded with EGCG (EGCGpNG) prepared by ultrasonication technique and investigated their effect in the treatment of bladder cancer both in vitro and in vivo [95]. Their results shown that this strategy induced high levels of cytotoxicity in bladder cancer cells (MBT-2) without affecting the viability of normal cells (Vero cells). Treatment with EGCG-pNG was shown to induce apoptosis through triggering the intrinsic apoptotic pathway through the activation of caspases- 3 and caspases- 7 and these were confirmed by in vivo studies. C3H/HeN mice subcutaneously implanted with MBT2 cells revealed significant higher reduction in tumor volume after oral ingestion of EGCG-pNG in comparison with free EGCG. In addition to this, nanoparticles were also administered through intratumoral and intraperitoneal route. These routes of administration were more effective than oral administration in suppressing tumor growth. The in vitro results showed that gold NPs induced nearly five-fold higher levels of apoptosis in B16F10 murine melanoma cells compared to nonencapsulated EGCG. The in vivo results demonstrated that intratumoral injection of EGCG NPs induced a reduction in the tumor volume of a mouse melanoma model compared with the control group. This ability to inhibit tumor growth was 1.6 times higher when EGCG was encapsulated compared to free EGCG [95].

\section{PLGA/PEG nanoparticles}

The EGCG encapsulated with polylactic acid-polyethylene glycol nanoparticles and found that encapsulated EGCG retains its biological effectiveness with over 10 -folds dose. The advantage for exerting its proapoptotic and growth suppressive effect, critically important determinants of chemopreventive effects of EGCG in both in vitro and in vivo systems. Hence, this study could serve as a basis for the use of nanoparticle-mediated delivery to enhance bioavailability and limit the toxicity of chemopreventive agents, such as EGCG [73]

\section{Nanospheres for bioavailability enhancement}

Nano BioSpheres Delivery System produced by the proprietary method, they are taken up more readily by cells than larger particles. Nanospheres are very small particles, measured in nanometers (nm), or billionths of a meter, that are now burgeoning into nutrient-delivery systems with diameters as small as $50 \mathrm{~nm}$ or even lower. Those showing greater efficacy are made of natural lipids, in which lipophilic compounds, such as the nutrients mentioned above, can readily dissolve [96].

\section{Liposomes}

Liposomes are vesicular drug delivery system forming a membranelike phospholipid bilayer enclosing an aqueous compartment. This vesicular delivery system facilitates to encapsulate both lipophilic and hydrophilic drugs with higher concentration. In addition, liposomes are biodegradable and present minimal levels of toxicity due to the biodegradable nature of the phospholipid membrane [97,98]. Fang et al., 2006, developed liposomes with EGCG for topical and intratumoral 
delivery to treat BCC (basal cell carcinoma) in female nude mice. The authors concluded that intratumoral injection of liposomes was the most effective route to succeed in cancer cells, promoting an excellent quantity of EGCG deposition in neoplastic cells. The same research group has also reported the applications of liposomal formulations for BCCs treatment in vivo after intratumoral administration. According to the authors Fang et al., 2006, that the nanoencapsulation of EGCG significantly increased the stability as compared to free drug, which may indicate that liposomes protect EGCG against oxidation and degradation. The synthesized liposomes also enabled higher EGCG accumulation in tumor tissues and induced higher levels of BCC cell death compared to the non-encapsulated EGCG treatment at lower concentrations [99].

Rashidinejada et al., 2014, encapsulated tea catechin and EGCG in soy phospholipid liposomes was examined at four different concentrations $(0 \%, 0.125 \%, 0.25 \%$, and $0.5 \% \mathrm{w} / \mathrm{v})$, and inclusion in cheese at $1 / 3$ and $0.25 \% \mathrm{w} / \mathrm{v}$. The empty capsules had a mean diameter of $133 \mathrm{~nm}$ and considerably $(\mathrm{p}<0.05)$ enlarged with the addition of catechin or EGCG. The microscopical investigation disclosed the lamellae and central core of the liposome and addition of antioxidants gave a big $(\mathrm{p}<0.05)$ increase within the size of liposomes. Liposome's had zeta potentials value in the range between -42.4 and $-46.1 \mathrm{mV}$ with no vital distinction between treatments, suggesting stable vesicle systems. High potency $(>70 \%)$ and yield $(\sim 80 \%)$ were achieved from the incorporation of catechin or EGCG within the vesicle structure [100].

\section{Phytosomes}

A phytosome is class of vesicular delivery system utilized to encapsulate the herbal extracts or isolated active principles with a phospholipid bilayer system used to administer both topically as well as orally. To overcome the low bioavailability and poor oral absorption of EGCG, Kazi Kazi et al., 2016, had formulated the catechin loaded nano phytosomes, newly acquainted forms of herbal formulations, with better bioavailability, entrapment efficiency, and stability using quality by design approach [101]. Catechins were extracted from green tea leaves using an aqueous solvent system at various temperature conditions. The concentration of EGCG in the extracted catechins was determined using ultra-performance liquid chromatography (UPLC) method. The obtained result from UPLC showed that $500 \mu \mathrm{g} / \mathrm{ml}$ EGCG was present in GTE. Particle size distribution data showed that phytosomes were in the range of 130-270 nm when characterized using Malvern Zetasizer and microscopic method. The rate and concentration of phospholipid were identified as critical process parameters and critical material attributes, respectively, affecting the quality attributes of phytosome. Formulations which proceeded at high addition rate exhibited smaller particle size and PDI compared to the formulations with low addition rate. The concentration of phospholipid has not influenced the particle size of phytosome at buffer $\mathrm{pH} 5.5$, while the increased concentration of phospholipid and buffer $\mathrm{pH} 7$ the particle size was decreased. The entrapment efficiencies for phytosome were in the range of $63-86 \%$, which was related to the size of the phytosomes. This study concluded that the phospholipid concentration and addition rate have marked an impact on average particle size, PDI, and encapsulation efficiency of nano phytosomes [101]

\section{Protein (oligomer) based nanoparticles}

IBN nanotechnology researchers have designed a therapeutic nanocarrier for drug delivery using novel compounds derived from EGCG. The core of this carrier is made of an oligomer of EGCG (OEGCG), which can encapsulate drugs and proteins, such as Herceptin, a protein drug currently used to treat breast cancer. Polyethylene glycol (PEG)EGCG was used to form the shell of this carrier. This novel compound is constituted of PEG, which is a known "stealth" polymer which acts to increase the circulation time of the carrier system, preventing it from being detected and filtered out of the body by the immune system before it reaches the tumor cell [102]. Micellar nanocomplexes $(\leq 100 \mathrm{~nm}$ in dimension) are formed from the OEGCG core and PEG-EGCG shell, protecting the protein drug from rapid proteolysis and renal clearance, while providing for tumor targeting. The research group conducted preclinical studies to evaluate the performance of IBN's green tea-based protein delivery system [103]. The study revealed that IBN's green tea nanocomplex loaded with Herceptin reduced tumor growth much more effectively when compared to administering Herceptin on its own. Using this nanocarrier, two-fold drug accumulated in the cancer cells, indicating an improved tumor targeting ability. At the same time, the drug accumulation in the other organs (liver, kidney, and lung) was lowered substantially. Green tea-based nanocarrier, in which the carrier itself displayed the anticancer effect, can boost the cancer efficacy when used together with the protein drugs. Author Motoichi Kurisawa developed green tea based nanocarrier drug delivery system to eradicate cancer and he had filed a patent for his formulations. The green tea-based micellar complexes are also being examined for the delivery of active ingredients in personal care and nutritional products [104].

\section{Nanoemulsion system}

Nanoemulsion is a suitable delivery system for nutrients to improve bioavailability by enhancing internal organ uptake. Kim et al., 2013, had established the inhibitory and hypolipidemic effects of nanoemulsified green tea extract (NGTE). The inhibitory effect was measured by a pair of $2^{\prime}$-azino-bis (3-ethylbenzthiazoline-6-sulfonic acid) (ABTS) radical scavenging assay and dichlorofluorescein diacetate (DCFH-DA) assay. C57BL/6 mice were fed an impression high-fat diet, GTE, or NGTE diet for 4 weeks. In composition analysis, GTE and NGTE contained similar total catechin concentrations. The antioxidative impact of GTE was comparable that of NGTE within the ABTS assay, GTE had a marked impact, though NGTE was more practical than GTE within the DCFHDA assay within the mouse feeding experiment, total and low-density lipoprotein cholesterin concentrations were considerably reduced when NGTE treatment as compared with GTE treatment in high-fat-fed C57BL/6J mice over the course of 4 weeks. The hypocholesterolemic effects were larger within the NGTE cluster compared with the GTE cluster $(24 \%$ vs. $15.4 \%$ cholesterol reduction compared with the control). Expression of 3-hydroxy-3-methylglutaryl coenzyme enzyme was considerably down-regulated. Super molecule expression of beta-lipoprotein receptor was considerably enlarged within the livers of each the GTE- and NGTE-treated groups $(+234.1 \%, \mathrm{p}<0.01$ and $+274.7 \%$, p $<0.001$ ), with a larger impact within the NGTE than within the GTE groups. These results suggested that nanoemulsion technique considerably promote the hypocholesterolemic efficacy of GTE in vivo attributable to enhance bioavailability [105].

\section{Liquid crystalline nanocomposite}

A liquid crystalline system (LCS) is a kind of nanostructured system accustomed incorporates various bioactive. Liquid crystals are identified since 1889 , once Lehmann represented AN intermediate state within the thermal transformation from solid to liquid state. Hence, a striking approach to beat this downside to safeguard the GTE is its incorporation into LCS and these drug delivery systems with completely different rheologic properties, since LCS have each fluid-liquid and crystalline-solid property. The in vivo inflammation assay disclosed that the less elastic and consistent LCS, F25E, and F32E given statistically constant medication activity compared to the positive management, decreasing considerably the paw swelling when $4 \mathrm{~h}$; whereas, the foremost structured and elastic LCS, powerfully restricted the potential effects of GTE. Thereby, the event of drug delivery systems with appropriate rheologic properties might enhance GTE bioavailability; sanction its administration through the skin for the treatment of inflammation [106].

\section{Lipid nanoparticles for cosmetics}

In year 2007, Grassland launched the supermolecule mainly based nanoparticles of Swiss cellular white illuminating eye essence. Swiss cellular white intensive ampoules that contain tea leaf extract, glycoprotein, herb root extract, horsetail extract, and viola extract [107].

\section{CONCLUSION}

Even though the health benefits of tea products are famed for thousands of years, basic analysis findings on its main phytoconstituent, EGCG, have 
well researched to be extraordinarily promising in various therapeutic benefits within the past decades. Moreover, the current data revealed that peoples from United States drinking large amounts of tea, or taking over-the-counter green tea extract product for desirable health benefits. From this review paper, we able to concluded that the potent EGCG has exposed to various nano drug delivery systems to improve the stability, rate of absorption and bioavailability. The polymeric nanoparticles, lipid-based nanoparticles, the vesicular system including liposomes, and phytosomes were adopted to develop green tea based products especially EGCG compound. The numerous health edges of EGCG as a prophylactic, however conjointly as a therapeutic, agent acting through totally different pathways are well documented within the literature. The conflict between in vitro and in vivo studies could also be thanks to its erratic bioavailability. Aspects regarding these facts, however conjointly with reference to dose levels, administration frequency and potential aspect effects stay to be addressed in future clinical trials.

\section{AUTHORS' CONTRIBUTIONS}

Satheesh Babu Natarajan, Suriyakala Perumal Chandran, Anjaneyulu Vinukonda, and Senthil Rajan D. have equally contributed for thematic preparation and editing of the manuscript.

\section{CONFLICTS OF INTEREST}

The authors declared that there are no conflicts of interest.

\section{REFERENCES}

1. Yadav D, Suri S, Choudhary AA, Sikender M, Hemant K, Beg NM. Novel approach: Herbal remedies and natural products in pharmaceutical science as nano drug delivery systems. Int J Pharm Tech 2011;3:3092-116.

2. Parasuraman S, Thing GS, Dhanaraj SA. Polyherbal formulation: Concept of Ayurveda. Pharmacogn Rev 2014:8:73-80.

3. Ganjhu RK, Mudgal PP, Maity H, Dowarha D, Devadiga S, Nag S, et al. Herbal plants and plant preparations as remedial approach for viral diseases. Virusdisease 2015;26:225-36.

4. Martin KW, Ernst E. Herbal medicines for treatment of bacterial infections: A review of controlled clinical trials. J Antimicrob Chemother 2003;51:241-6.

5. Calixto JB. Efficacy, safety, quality control, marketing and regulatory guidelines for herbal medicines (phytotherapeutic agents). Braz J Med Biol Res 2000;33:179-89.

6. Clement YN, Williams AF, Khan K, Bernard T, Bhola S, Fortuné M, et al. A gap between acceptance and knowledge of herbal remedies by physicians: The need for educational intervention. BMC Complement Altern Med 2005;5:20.

7. Ekor M. The growing use of herbal medicines: Issues relating to adverse reactions and challenges in monitoring safety. Front Pharmacol 2014;4:177.

8. Piyush M, Vividha D. A comprehensive review on pharmacokinetic profile of some traditional Chinese medicines. New J Sci 2016;1:1-31.

9. Lorkowski G. Gastrointestinal absorption and biological activities of serine and cysteine proteases of animal and plant origin: Review on absorption of serine and cysteine proteases. Int J Physiol Pathophysiol Pharmacol 2012;4:10-27.

10. Rein MJ, Renouf M, Cruz-Hernandez C, Actis-Goretta L, Thakkar SK, da Silva Pinto M, et al. Bioavailability of bioactive food compounds: A challenging journey to bioefficacy. Br J Clin Pharmacol 2013; 75:588-602.

11. Jahangirian H, Lemraski EG, Webster TJ, Rafiee-Moghaddam R, Abdollahi Y.A review of drug delivery systems based on nanotechnology and green chemistry: Green nanomedicine. Int J Nanomedicine 2017; 12:2957-78.

12. Din FU, Aman W, Ullah I, Qureshi OS, Mustapha O, Shafique S, et al. Effective use of nanocarriers as drug delivery systems for the treatment of selected tumors. Int J Nanomedicine 2017;12:7291-309.

13. Arruebo M, Fernandez-Pacheco R, Ibarra MR, Santamaria J. Magnetic nanoparticles for drug delivery. Nano Today 2007;2:22-32.

14. Khan N, Mukhtar H. Tea and health: Studies in humans. Curr Pharm Des 2013;19:6141-7.

15. Mukhtar H, Ahmad N. Tea polyphenols: Prevention of cancer and optimizing health. Am J Clin Nutr 2000;71:1698S-702S.

16. Costa LM, Gouveia ST, Nóbrega JA. Comparison of heating extraction procedures for $\mathrm{Al}, \mathrm{Ca}, \mathrm{Mg}$, and $\mathrm{Mn}$ in tea samples. Anal Sci 2002;18:313-8

17. Rietveld A, Wiseman S. Antioxidant effects of tea: Evidence from human clinical trials. J Nutr 2003;133:3285S-3292S.

18. Sabu MC, Priya TT, Ramadasan K, Ikuo N. Beneficial effects of green tea: A literature review. Chin Med 2010;5:1-9.

19. Taylor PW, Hamilton-Miller JM, Stapleton PD. Antimicrobial properties of green tea catechins. Food Sci Technol Bull 2005;2:71-81.

20. Sharangi AB. Medicinal and therapeutic potentialities of tea (Camellia sinensis L). A review. Food Res Int 2009:42:529-35.

21. Ahmed S, Stepp JR, Orians C, Griffin T, Matyas C, Robbat A, et al. Effects of extreme climate events on tea (Camellia sinensis) functional quality validate indigenous farmer knowledge and sensory preferences in tropical China. PLoS One 2014;9:e109126.

22. Wanda CR. An update on the health benefits of green tea. Beverages 2017;3;1-14.

23. Paini SW, Werdani YD, Christine S, Kartikasari A. In vitro antioxidant capacities and antidiabetic properties of Pluchea leaves and green tea mixtures at various proportions. Int J Pharm Pharm Sci 2015;9:203-8.

24. Chu C, Deng J, Man Y, Qu Y. Green tea extracts epigallocatechin-3gallate for different treatments. Biomed Res Int 2017;2017:5615647.

25. Chacko SM, Thambi PT, Kuttan R, Nishigaki I. Beneficial effects of green tea: A literature review. Chin Med 2010;5:13

26. Tomás-Barberán FA, Andrés-Lacueva C. Polyphenols and health: Current state and progress. J Agric Food Chem 2012;60:8773-5.

27. Singh BN, Shankar S, Srivastava RK. Green tea catechin, epigallocatechin-3-gallate (EGCG): Mechanisms, perspectives and clinical applications. Biochem Pharmacol 2011;82:1807-21.

28. Lucilene DM, Tiele GT. Influence of permanganate index in the parameters as total phenol content and total antioxidant activity of extracts of Camellia sinensis. Int J Pharm Pharm Sci 2017;9:110-3.

29. Jabeen S, Sahib A, Maria S, Waqar A, Rukhsana B, Farrukh SH, et al. Withering timings affect the total free amino acids and mineral contents of tea leaves during black tea manufacturing. Arab J Chem 2015. Doi: 10.1016/j.arabjc.2015.03.011.

30. Yumen H. Morphology, manufacturing, types, composition and medicinal properties of tea (Camellia sinensis). J Basic Appl Plant Sci 2017;1:1-10.

31. Lee LS, Kim SH, Kim YB, Kim YC. Quantitative analysis of major constituents in green tea with different plucking periods and their antioxidant activity. Molecules 2014;19:9173-86.

32. Rabiatul AZ, Nurliyana AR, Faridah AB. Determination of flavonoid and caffeine content in black and oolong teas. J Sci Technol 2016; $8: 18-24$.

33. Sanderson WG, Grahamm NH. Formation of black tea aroma. J Agric Food Chem 1973;21:576-85

34. Sinija VR, Mishra HN. Green tea: Health benefits. J Nutr Environ Med 2008; 17:232-42

35. Ansari SH, Islam F, Sameem M. Influence of nanotechnology on herbal drugs: A review. J Adv Pharm Technol Res 2012;3:142-6.

36. Krishnasis C, Arun S, Sundaram R. Nano-technology in herbal medicines: A review. Int J Herb Med 2016;4:21-7.

37. Singh RP, Singh SG, Naik H, Jain D, Bisla S. Herbal excipients in novel drug delivery system. Int J Compr Pharm 2011;2:1-7.

38. Sungthongjeen S, Pitaksuteepong T, Somsiri A, Sriamornsak P. Studies on pectins as potential hydrogel matrices for controlled-release drug delivery. Drug Dev Ind Pharm 1999;25:1271-6.

39. Bonifácio BV, Silva PB, Ramos MA, Negri KM, Bauab TM, Chorilli M, et al. Nanotechnology-based drug delivery systems and herbal medicines: A review. Int J Nanomedicine 2014;9:1-5.

40. Chandirika JU, Sindhu R, Selvakumar S, Annadurai G. Herbal extract encapsulated in chitosan nanoparticle: A novel strategy for the treatment of urolithiasis. Indo Am J Pharm Sci 2018;5:1955-61.

41. Vani M, Amukta MA, Padmalatha K. Nanoparticles for herbal extracts. Asian J Pharm 2016;10:S54-60.

42. Martínez-Ballesta M, Gil-Izquierdo Á, García-Viguera C, DomínguezPerles R. Nanoparticles and controlled delivery for bioactive compounds: Outlining challenges for new "smart-foods" for health. Foods 2018;7:e72.

43. Viktor N, Kalusevica A, Verica M, Steva L, Branko B. An overview of encapsulation technologies for food applications. Proc Food Sci 2011; 1:1806-15.

44. Lambert JD, Yang CS. Cancer chemopreventive activity and bioavailability of tea and tea polyphenols. Mutat Res 2003; 523-524:201-8.

45. Chen Z, Zhu QY, Tsang D, Huang Y. Degradation of green tea catechins in tea drinks. J Agric Food Chem 2001;49:477-82. 
46. Mereles D, Hunstein W. Epigallocatechin-3-gallate (EGCG) for clinical trials: More pitfalls than promises? Int J Mol Sci 2011;12:5592-603.

47. Lambert JD, Lee MJ, Lu H, Meng X, Hong JJ, Seril DN, et al. Epigallocatechin-3-gallate is absorbed but extensively glucuronidated following oral administration to mice. J Nutr 2003;133:4172-7.

48. Cai ZY, Li XM, Liang JP, Xiang LP, Wang KR, Shi YL, et al. Bioavailability of tea catechins and its improvement. Molecules 2018; 23:e2346.

49. Lu H, Meng X, Li C, Sang S, Patten C, Sheng S, et al. Glucuronides of tea catechins: Enzymology of biosynthesis and biological activities. Drug Metab Dispos 2003;31:452-61.

50. Hong J, Lambert JD, Lee SH, Sinko PJ, Yang CS. Involvement of multidrug resistance-associated proteins in regulating cellular levels of (-)-epigallocatechin-3-gallate and its methyl metabolites. Biochem Biophys Res Commun 2003;310:222-7.

51. Roberts JD, Roberts MG, Tarpey MD, Weekes JC, Thomas CH. The effect of a decaffeinated green tea extract formula on fat oxidation, body composition and exercise performance. J Int Soc Sports Nutr 2015;12:1.

52. Chow HH, Hakim IA, Vining DR, Crowell JA, Ranger-Moore J, Chew WM, et al. Effects of dosing condition on the oral bioavailability of green tea catechins after single-dose administration of polyphenon E in healthy individuals. Clin Cancer Res 2005;11:4627-33.

53. Lin LC, Wang MN, Tseng TY, Sung JS, Tsai TH. Pharmacokinetics of (-)-epigallocatechin-3-gallate in conscious and freely moving rats and its brain regional distribution. J Agric Food Chem 2007;55:1517-24.

54. Catterall F, King LJ, Clifford MN, Ioannides C. Bioavailability of dietary doses of $3 \mathrm{H}$-labelled tea antioxidants (+)-catechin and (-)-epicatechin in rat. Xenobiotica 2003;33:743-53.

55. Lambert JD, Sang S, Yang CS. Biotransformation of green tea polyphenols and the biological activities of those metabolites. Mol Pharm 2007;4:819-25.

56. Huo C, Wan SB, Lam WH, Li L, Wang Z, Landis-Piwowar KR, et al. The challenge of developing green tea polyphenols as therapeutic agents. Inflammopharmacology 2008;16:248-52.

57. Lambert JD, Sang S, Hong J, Kwon SJ, Lee MJ, Ho CT, et al. Peracetylation as a means of enhancing in vitro bioactivity and bioavailability of epigallocatechin-3-gallate. Drug Metab Dispos 2006; 34:2111-6.

58. Stalmach A, Mullen W, Steiling H, Williamson G, Lean ME, Crozier A, et al. Absorption, metabolism, and excretion of green tea flavan-3-ols in humans with an ileostomy. Mol Nutr Food Res 2010;54:323-34.

59. Stalmach A, Troufflard S, Serafini M, Crozier A. Absorption, metabolism and excretion of choladi green tea flavan-3-ols by humans. Mol Nutr Food Res 2009;53 Suppl 1:S44-53.

60. Friedman M, Levin CE, Lee SU, Kozukue N. Stability of green tea catechins in commercial tea leaves during storage for 6 months. J Food Sci 2009;74:H47-51.

61. Qin YZ, Anqi Z, David T, Yu H, Zhen-Yu C. Stability of green tea catechins. J Agric Food Chem 1997;45:4624-8.

62. Lestari AB, Trisusilawati MY. The effect of fumaric acid-sodium bicarbonate on the green tea effervescent granule's quality made by dry granulation. Indones J Pharm 2010;21:209-17.

63. Krook MA, Hagerman AE. Stability of polyphenols epigallocatechin gallate and pentagalloyl glucose in a simulated digestive system. Food Res Int 2012;49:112-6.

64. Zhang L, Zheng Y, Chow MS, Zuo Z. Investigation of intestinal absorption and disposition of green tea catechins by caco-2 monolayer model. Int J Pharm 2004;287:1-2.

65. Owuor PO, Nyirenda HE, Wilson L. Influence of region of production on clonal black tea chemical characteristics. Food Chem 2008; 108:263-71.

66. Hirun S, Roach PD. A study of stability of (-)-Epigallocatechin gallate (EGCG) from green tea in a frozen product. Int Food Res J 2011; 18:1261-4.

67. Nurlaela E, Sugihartini N, Ikhsanudin A. Optimasi komposisi tween 80 dan span 80 sebagai emulgator dalam repelan minyak atsiri daun sere (Cymbopogon citratus (DC) Stapf) terhadap nyamuk Aedes aegypti BETINA PADA basis vanishing cream dengan metode simplex lattice design. Pharmaciana 2012;2:41-54.

68. Prayong P, Weerapreeyakul N, Sripanidkulch B. Validation of isocratic eluting and stepwise flow rate gradient for HPLC determination of catechins, gallic acid and caffeine in tea. Science Asia 2007;33:113-17.

69. Thomson WN, Fudholi A, Sudarsono, Setyowati EP. Stability of epigallocatechin gallate (EGCG) from green tea (Camellia sinensis) and its antibacterial activity against Staphylococcus epidermidis ATCC 35984 and propionibacterium acnes ATCC 6919. Asian J Biol Sci
2015;8:93-101.

70. Hirun S, Roach PD. An improved solvent extraction method for the analysis of catechins and caffeine in green tea. J Food Nutr Res 2011;50:160-6.

71. Wang R, Zhou W, Wen RA. Kinetic study of the thermal stability of tea catechins in aqueous systems using a microwave reactor. J Agric Food Chem 2006;54:5924-32

72. Tatsiana GS, Shantanu SB, Pranitha V. Layer-by-layer-coated gelatin nanoparticles as a vehicle for delivery of natural polyphenols. ACS Nano 2009;3:1877-85

73. Siddiqui IA, Adhami VM, Bharali DJ, Hafeez BB, Asim M, Khwaja SI, et al. Introducing nanochemoprevention as a novel approach for cancer control: Proof of principle with green tea polyphenol epigallocatechin3-gallate. Cancer Res 2009;69:1712-6.

74. Ana PR, Marcos AE, Camila BT, Pietro C. Biomedical applications of nanotechnology. Biophys Rev 2017;9:79-89.

75. Rizvi SAA, Saleh AM. Applications of nanoparticle systems in drug delivery technology. Saudi Pharm J 2018;26:64-70.

76. Aura-Ileana M, Teresa G, Rosa-Elvira N, Laura-Susana A, Castaño V. Polymeric and ceramic nanoparticles in biomedical applications. J Nanotechnol 2012;1:10

77. Alotaibi A, Bhatnagar P, Najafzadeh M, Gupta KC, Anderson D. Tea phenols in bulk and nanoparticle form modify DNA damage in human lymphocytes from colon cancer patients and healthy individuals treated in vitro with platinum-based chemotherapeutic drugs. Nanomedicine (Lond) 2013;8:389-401.

78. Elsabahy M, Wooley KL. Design of polymeric nanoparticles for biomedical delivery applications. Chem Soc Rev 2012;41:2545-61.

79. Yang CS, Wang X, Lu G, Picinich SC. Cancer prevention by tea: Animal studies, molecular mechanisms and human relevance. Nat Rev Cancer 2009;9:429-39.

80. Dube A, Nicolazzo JA, Larson I. Chitosan nanoparticles enhance the intestinal absorption of the green tea catechins $(+)$-catechin and (-)-epigallocatechin gallate. Eur J Pharm Sci 2010;41:219-25.

81. Manea AM, Andronescu C, Meghea A. Green tea extract loaded into solid lipid nanoparticles. UPB Sci Bull Series B 2014;76:125-36.

82. Wang S, Noh SK, Koo SI. Green tea catechins inhibit pancreatic phospholipase $\mathrm{A}(2)$ and intestinal absorption of lipids in ovariectomized rats. J Nutr Biochem 2006;17:492-8

83. Gopal J, Muthu M, Paul D, Kim DH, Chun S. Bactericidal activity of green tea extracts: The importance of catechin containing nano particles. Sci Rep 2016;6:19710.

84. Chyu KY, Babbidge SM, Zhao X, Dandillaya R, Rietveld AG, Yano J, et al. Differential effects of green tea-derived catechin on developing versus established atherosclerosis in apolipoprotein E-null mice. Circulation 2004;109:2448-53.

85. De Pace RC, Liu X, Sun M, Nie S, Zhang J, Cai Q, et al. Anticancer activities of (-)-epigallocatechin-3-gallate encapsulated nanoliposomes in MCF7 breast cancer cells. J Liposome Res 2013;23:187-96.

86. Barras A, Mezzetti A, Richard A, Lazzaroni S, Roux S, Melnyk P, et al. Formulation and characterization of polyphenol-loaded lipid nanocapsules. Int J Pharm 2009;379:270-7.

87. Wang S, Su R, Nie S, Sun M, Zhang J, Wu D, et al. Application of nanotechnology in improving bioavailability and bioactivity of dietderived phytochemicals. J Nutr Biochem 2014;25:363-76.

88. Zhang J, Nie S, Wang S. Nanoencapsulation enhances epigallocatechin3 -gallate stability and its antiatherogenic bioactivities in macrophages. J Agric Food Chem 2013;61:9200-9.

89. Pradeep P, Chulkyoon M, Sanghoon K, Liang J, Neeraja R. Nanotechnological approaches to enhance the bioavailability and therapeutic efficacy of green tea polyphenols. J Funct Foods 2017; 34:139-51.

90. Shi M, Shi YL, Li XM, Yang R, Cai ZY, Li QS, et al. Food-grade encapsulation systems for (-)-epigallocatechin gallate. Molecules 2018; $23: 445$

91. Hong J, Lu H, Meng XF, Ryu JH, Hara Y, Yang CS Stability, cellular uptake, biotransformation, and efflux of tea polyphenol (-)-epigallocatechin-3-gallate in ht-29 human colon adenocarcinoma cells. Cancer Res 2002;62:7241-6.

92. Dube A, Nicolazzo JA, Larson I. Chitosan nanoparticles enhance the plasma exposure of (-)-epigallocatechin gallate in mice through an enhancement in intestinal stability. Eur J Pharm Sci 2011;44:422-6.

93. Sharma RK, Shikha G, Shilpa M. Preparation of gold nanoparticles using tea: A green chemistry experiment. J Chem Educ 2012;89:1316-8.

94. Nune SK, Chanda N, Shukla R, Katti K, Kulkarni RR, Thilakavathi S, et al. Green nanotechnology from tea: Phytochemicals in tea as building blocks for production of biocompatible gold nanoparticles. J Mater 
Chem 2009;19:2912-20.

95. Hsieh DS, Wang H, Tan SW, Huang YH, Tsai CY, Yeh MK, et al. The treatment of bladder cancer in a mouse model by epigallocatechin-3gallate-gold nanoparticles. Biomaterials 2011;32:7633-40.

96. Hearnden V, Sankar V, Hull K, Juras DV, Greenberg M, Kerr AR, et al. New developments and opportunities in oral mucosal drug delivery for local and systemic disease. Adv Drug Deliv Rev 2012;64:16-28.

97. Dag D, Oztop MH. Formation and characterization of green tea extract loaded liposomes. J Food Sci 2017;82:463-70.

98. Zou LQ, Peng SF, Liu W, Gan L, Liu WL, Liang RH, et al. Improved in vitro, digestion stability of (-)-epigallocatechin gallate through nanoliposome encapsulation. Food Res Int 2014;64:492-9.

99. Fang JY, Lee WR, Shen SC, Huang YL. Effect of liposome encapsulation of tea catechins on their accumulation in basal cell carcinomas. J Dermatol Sci 2006;42:101-9.

100. Rashidinejad A, Birch EJ, Sun-Waterhouse D, Everett DW. Delivery of green tea catechin and epigallocatechin gallate in liposomes incorporated into low-fat hard cheese. Food Chem 2014;156:176-83.

101. Kazi AS, Tanzia T, Kazi M, Reza H, Mohammad S. Proceedings of the AAPS Annual Meeting and Exposition. Denver: Formulation and Optimization of Epigallocatechin Gallate (EGCG) Nano Drug Delivery System Using QbD Approach; 2016.
102. Chung JE, Tan S, Gao SJ, Yongvongsoontorn N, Kim SH, Lee JH, et al. Self-assembled micellar nanocomplexes comprising green tea catechin derivatives and protein drugs for cancer therapy. Nat Nanotechnol 2014; 9:907-12.

103. Tan S. Self Assembled Nanocomplexes Comprising of Green Tea Catechin Derivatives and Protein Drugs for Cancer Therapy. Ph.D Dissertation. London: Imperail College London; 2014.

104. Green Tea Based Nanocarrier Kills Cancer Cells More Effectively. Singapore: Institute of Bioengineering and Nanotechnology Singapore; 2014. Available from: https://www.a-star.edu.sg/Newsand-Events/News/Press-releases/ID/3640/IBN-develops-green-teabased-missiles-to-kill-cancer-cells-more-effectively.aspx.

105. Kim YJ, Houng SJ, Kim JH, Kim YR, Ji HG, Lee SJ, et al. Nanoemulsified green tea extract shows improved hypocholesterolemic effects in C57BL/6 mice. J Nutr Biochem 2012;23:186-91.

106. Patricia BS, Giovana MF, João AO. Structural features and the antiinflammatory effect of green tea extract-loaded liquid crystalline systems intended for skin delivery. Polymers 2017;9:1-19.

107. Attama AA, Momoh MA, Builders PF. Lipid Nanoparticulate Drug Delivery Systems: A Revolution in Dosage form Design and Development. Rijeka, Croatia: Intech Open Access Publisher; 2012. 